\title{
REDUCING INCOMPARABILITY IN MULTICRITERIA DECISION ANALYSIS: AN EXTENSION OF THE ZAPROS METHOD
}

\author{
Isabelle Tamanini and Plácido Rogério Pinheiro*
}

Received December 18, 2008 / Accepted November 25, 2010

\begin{abstract}
The ZAPROS method belongs to the Verbal Decision Analysis framework, and it aims at solving decision-making problems in a more realistic way from the decision maker's point of view. Quantitative methods can lead to loss of information when attempting to assign accurate measurements to verbal values. However, the feature exposed can cause a decrease in the comparison power of the method, making the incomparability cases between the alternatives unavoidable and leading to an unsatisfactory result of the problem, thus leading to an unsatisfactory outcome of the problem. Considering the limitation exposed, this work presents a methodological approach structured on the ZAPROS method to assist in decisionmaking in the Verbal Decision Analysis. The aim is to produce a complete result which is satisfactory to the decision maker, through the reduction of the cases of incomparability between alternatives. The modifications were mainly applied to the comparison of alternatives process and did not change the computational complexity of the method.
\end{abstract}

Keywords: ZAPROS method, verbal decision analysis, incomparability problem.

\section{INTRODUCTION}

One of the major problems faced by organizations concerns the decision-making process. Determining the object which will lead to the best result is not a trivial process and involves the analysis of several factors. Due to human limitations and to the complex nature of the problems, it is practically impossible to consider all the relevant aspects for decision-making. This process becomes even more critical when it is related to management decisions, since the choice of an inaccurate alternative may lead to a waste of resources, thus affecting the company.

The decision-making scenario, which involves the analysis of objects from several points of view, is assisted by multicriteria methodologies. These help to generate knowledge on the decision context, thus increasing the decision maker's confidence (Evangelou et al., 2005). The

*Corresponding author

University of Fortaleza (UNIFOR), Graduate Program in Applied Computer Sciences, Av. Washington Soares, 1321 B1. J, S1. 30, 60811-905 Fortaleza, CE, Brazil. E-mails: isabelle.tamanini@gmail.com, placido@unifor.br 
multicriteria methods can be based on either the quantitative or qualitative analysis of the problem; therefore, choosing the approach that best suits the problem to be solved becomes a great challenge. Castro et al. (2009), Nunes et al. (2011) and Pinheiro et al. (2008), to name but a few, present problems to which the quantitative methods have been applied. Among those that apply the qualitative ones, we can mention Mendes et al. (2008), Tamanini et al. (2009a), Tamanini et al. (2011) Tamanini et al. (2009b), Tamanini et al. (2009c), Tamanini et al. (2010c), Tamanini et al. (2010d) and Gomes et al. (2010).

A great advantage of the qualitative methods over the quantitative ones is that all the questionings made in eliciting the preference process are presented in the decision maker's natural language. Moreover, verbal descriptions are used to measure the preference levels. This procedure is psychologically valid, for it respects the limitations of the human information processing system.

The Verbal Decision Analysis (VDA) framework (Moshkovich et al., 2005) is structured on the realization that most decision-making problems can be verbally described. This framework involves three main methods: PACOM, ORCLASS and ZAPROS, the best known among others.

The PACOM (PAired COMpensation) method (Larichev \& Moshkovich, 1997) aims at supporting the decision-making process in scenarios involving a great number of criteria, a rather small set of alternatives (no more than 10) and in which the latter are difficult to be analyzed without a formal method. In problems where the number of alternatives is greater than 10 , the set should be reduced through the application of more robust methods to determine a subset containing the potentially best alternatives. Tamanini et al. (2010a) applies the PACOM method to sort out of a set of questionnaires from the most appropriate for determining a possible case of the Alzheimer's disease, to the least one.

The ORCLASS (ORdinal CLASSification) method (Larichev \& Moshkovich, 1997) aims at classifying the alternatives of a given set. The method can be used to obtain a definite decision rule, considering a set of criteria and their values, so that any alternative represented by these can be classified. An application of the method can be found in Gomes et al. (2010). The method is used to aid in the decision-making concerning the choice of advertising media alternatives for the strategic marketing plan of a small Brazilian company.

On the other hand, the ZAPROS method (Larichev, 2001), which is the focus of this work, aims at ranking multicriteria alternatives in scenarios involving a rather small set of criteria and criteria values, and a greater number of alternatives.

The main characteristic of the Verbal Decision Analysis methods, however, brings about some limitations: the incomparability cases become inevitable when the scale of preferences is purely verbal, since there is no accurate measure of the values. Therefore, the method may not achieve satisfactory results in some situations, thus presenting an incomplete outcome to the problem.

Considering the aforementioned limitation, this paper presents a methodological approach, mainly structured on the ZAPROS method, for aiding in the decision-making process on Verbal Decision Analysis. The aim is to present a complete and satisfactory result to the decider through 
reducing the incomparability cases between alternatives. The method was chosen among other available methods because it suits the characteristics of the contexts questioned, considering the evaluation of the problem, the decision objects and the available information. The modifications were applied mainly to the comparison of alternatives process and did not modify the computational complexity of the method.

According to Manouselis \& Costopoulou (2008), the testing of multicriteria methods, also called multicriteria recommender, can be facilitated by means of tools that implement the recommendation algorithms. This way, the Aranau tool, a decision supporting system structured on the modified methodology, was implemented in order to verify the improvements achieved in the comparison of the alternatives and, consequently, in the comparison power of the method, considering the modifications applied to the ZAPROS method. This validation will be made through the application of some multicriteria problems previously structured on the method.

\section{THE ZAPROS METHODOLOGY}

The ZAPROS methodology belongs to the Verbal Decision Analysis (VDA) framework and aims at classifying given multicriteria alternatives. The methods are structured on the realization that most decision-making problems can be verbally described. The Verbal Decision Analysis supports the decision-making process by verbally presenting the problem (Larichev \& Moshkovich, 1997).

The methodology involves the following methods: ZAPROS LM, ZAPROS III and STEPZAPROS. The ZAPROS LM method is structured in three stages: Problem Formulation, Elicitation of Preferences and Comparison of Alternatives. The relevant criteria for decision-making, the criteria values and the preferences scale based on the decision maker's preference are obtained on the first and second stages. The elicitation of preferences process is made by comparing the vectors of the alternatives. After that, the real alternatives to the problem and the values of the criteria they represent will be defined. The value of each alternative can be obtained based on the weight of the criteria values on the preference scale. Then, it is possible to rank-order the alternatives.

The ZAPROS III method is based on the elicitation of preferences around the values that represent the distance between the evaluations of two criteria. It is an evolution of the ZAPROS LM method, applying a modified version of the procedure, which makes it more efficient and consistent.

In the STEP-ZAPROS method, only the real alternatives to the problem are considered upon establishing the scale of preferences (in the ZAPROS LM and the ZAPROS III method, a complete rule of preferences is structured). Besides, new questionings will be made when the decision maker's information is not enough to compare the alternatives which are relevant to the problem. The application of the method is interactive and structured on three steps, which will only be performed when necessary; i.e., when it is not possible to find the solution to the problem after 
the first step, the second step will be applied. This characteristic has originated the name of the method, STEP-ZAPROS.

This work focuses on the ZAPROS III method, which is based on the elicitation of preferences around values that represent the distance between the evaluations of two criteria. The elicitation of preferences is performed in such a way that a decision rule can be structured before defining the alternatives. This characteristic makes the method more generic and new alternatives can be included without the necessity to change the scale of preferences. As a Verbal Decision Analysis method, comparisons between the criteria will be made by human beings, symbolizing the decision maker, who also verbally defines the quality graduations of the criteria values.

Among the advantages of the ZAPROS III method, we can say that (Ustinovich \& Kochin, 2004):

- It presents questions on the elicitation of the preference process which are understandable to the decision maker, based on criteria values. This procedure is psychologically valid, for it respects the limitations of the human information processing system, and represents the method's greatest feature;

- It presents considerable resistance to the decision maker's contradictory inputs, being capable of detecting and requesting a solution to these problems;

- It specifies all the information of the qualitative comparison in a language that is understandable to the decision maker.

One disadvantage of the method is that the number of criteria and the values of the criteria supported are limited, since they are responsible for the exponential growth of the possible alternatives to the problem and, thus, of the information required in the process of eliciting preferences.

The preference scale is essentially qualitative and is defined with verbal variables, which causes losses in the comparison power, since these symbols are not assigned exact values (which implies in the inexistence of overall values - best or worst in any kind of situation) and cannot be computationally recognized. This results in a lot of incomparable alternatives, which can lead to an incomplete outcome.

According to Larichev (2001b), an estimate of the number of incomparable alternatives (and, consequently, of the decision capacity of the method) can be made by calculating the number of pairs of alternatives $\left(Q=0.5 n^{N}\left(n^{N}-1\right)\right.$, where $N$ represents the number of criteria and $n$ is the number of criteria values) and the subset that will be related by the Pareto's dominance rule $(D)$. From the difference between $Q$ and $D$, we have the set of alternatives that depends directly on the preference scale obtained by the decision maker's answers. This is the set which is most likely to present contradictory pairs of alternatives. After that, the index of the decision capacity of the method can be obtained as follows: $P=1-S / B$, where $B$ is the difference between $Q$ and $D$, and $S$ is the number of alternatives that cannot be compared based on the decider's preference scale (the incomparable alternatives). 
In Dimitriadi \& Larichev (2005), a system implemented in Visual C++ 6.0 and structured on the ZAPROS III method is presented; and an analysis of the method's performance is made. The Formal Index of Quality (FIQ), which allows the reduction of the number of comparisons between the alternatives in the classification process, was not applied.

The system presented in Ashikhmin \& Furems (2004), UniComBOS, aims at avoiding the existing limitations of the other methods. The rule for the consistency control of the decision maker's answers was modified in order to improve it by using procedures beyond the transitivity relations. It represents the implementation of a new procedure for the comparison and classification of multicriteria alternatives.

The questions made during the elicitation of preferences process involve only the criteria values necessary to the comparison of the alternatives defined (which values are preferable, which are equivalent, etc.). After this process, the result obtained to the problem will be shown to the user.

As the tool is based on the elicitation of preferences after the definition of the alternatives, there is no previously formulated decision rule, unlike in the ZAPROS LM and in the ZAPROS III method. An advantage of this implementation is that the incomparability cases can be avoided. On the other hand, if a new alternative is either defined or changed, the scale of preferences will have to be reevaluated and, possibly, modified. Therefore, this is not the most appropriate tool for scenarios of simulation, where, for instance, the objects will constantly be modified; for cases on which there is no direct contact with either the decision maker; or for cases where the alternatives of the problem are not previously known (as in a decision-making model involving computational agents).

\section{THE APPROACH METHODOLOGY FOR REDUCING THE INCOMPARABILITY CASES: THE ZAPROS III-i METHOD}

A modification to the ZAPROS III method (Larichev, 2001) is proposed. The ZAPROS III- $i$ method presents three main stages: Problem Formulation, Elicitation of Preferences and Comparison of Alternatives, as proposed in the main version of the ZAPROS method. These stages are described as follows.

\subsection{Formal Statement of the Problem}

The methodology follows the problem formulation proposed in Larichev (2001), where:

- $K=1,2, \ldots, N$, representing a set of $N$ criteria;

- $n_{q}$ represents the number of possible values on the scale of $q$-th criterion, $(q \in K)$; for the ill-structured problems, as in this case, usually $n_{q}=4$;

- $X_{q}=x_{i q}$ represents a set of values to the $q$-th criterion, which is this criterion scale; $\left|X_{q}\right|=n_{q}(q \in K)$; where the values of the scale are decreasingly ordered, from best to worst, regardless of the values of other scales; 
- $Y=X_{1} * X_{2} * \cdots * X_{n}$ represents a set of vectors $y_{i}$, such that: $y_{i}=\left(y_{i 1}, y_{i 2}, \ldots, y_{i N}\right)$, and $y_{i} \in Y, y_{i q} \in X_{q}$ and $P=|Y|$, where $|Y|=\prod_{i=1}^{i=N} n_{i}$;

- $A=\left\{a_{i}\right\} \in Y, i=1,2, \ldots, t$, where the set of $t$ vectors represents the description of the real alternatives.

As the outcome of the problem, the multicriteria alternatives ordering based on the decision maker's preferences is required.

\subsection{Elicitation of Preferences}

In this stage, the scale of preferences for quality variations (Joint Scale of Quality Variations JSQV) is structured. The elicitation of preferences follows the order of steps shown in Figure 1 (Tamanini \& Pinheiro, 2008).

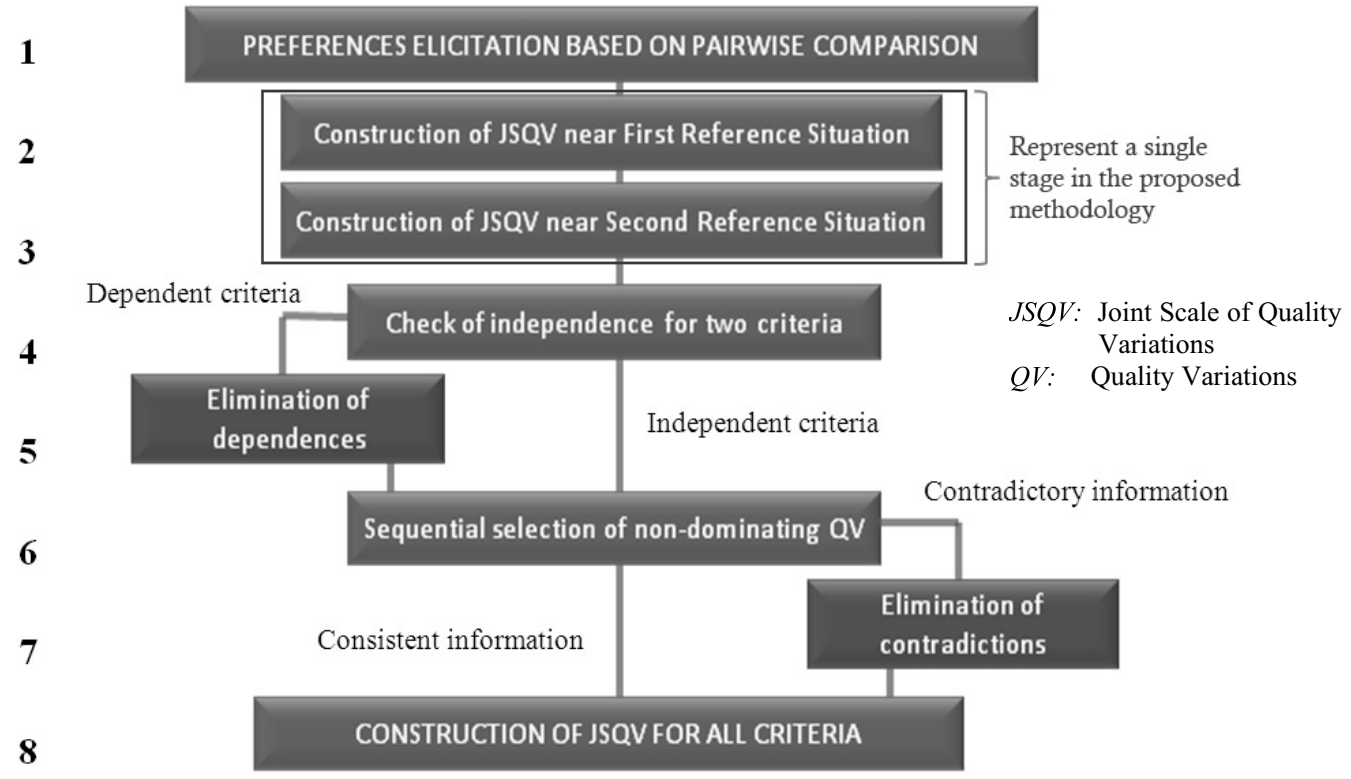

Figure 1 - Elicitation of preferences process.

The structure presented is the same proposed in the ZAPROS III method (Larichev, 2001), however, substages 2 and 3 (numbered on the left side of the figure) were put together in just one substage.

Instead of setting the decision maker's preferences based on the first reference situation and, then, establishing another scale of preferences using the second reference situation, we propose that the two substages be transformed into one. The questions made considering the first reference situation are the same of the ones made considering the second reference situation. So, both situations will be presented and must be considered in the answer to the question, in order not to 
cause criteria dependence. The alteration reflects on the improvement of the process: instead of making $2 n$ questions, only $n$ will be made.

The questions to Quality Variations $(\mathrm{QV})$ belonging to just one criteria will be made as follows: supposing a criterion A having $X_{A}=\left\{A_{1}, A_{2}, A_{3}\right\}$, the decision maker will be asked about his preferences between the QV $a_{1}-a_{2}, a_{1}-a_{3}$ and $a_{2}-a_{3}$. Thus, there is a maximum of three questions to a criterion with three values $\left(n_{q}=3\right)$.

The question will be formulated in a different way on the elicitation of preferences of two criteria, because there were difficulties understanding the questionings and delay in the decision maker's answers when exposing QVs from different criteria. This way, the question will be made dividing the QV into two items. For example, having the set of criteria $\mathrm{k}=\{\mathrm{A}, \mathrm{B}, \mathrm{C}\}$, where $n_{q}=3$ and $X_{q}=\left\{q_{1}, q_{2}, q_{3}\right\}$, considering the pair of criteria A, B and the QV $a_{1}$ and $b_{1}$, the decision maker should analyze which imaginary alternative would be preferable: $A_{1}, B_{2}, C_{1}$ or $A_{2}, B_{1}, C_{1}$. However, this answer must be the same to alternatives $A_{1}, B_{2}, C_{3}$ and $A_{2}, B_{1}, C_{3}$. If the decision maker answers that the first option is better, then $b_{1}$ is preferable to $a_{1}$, because having value $B_{2}$ on the alternative is preferable to having $A_{2}$.

\subsection{Comparison of Alternatives}

With the aim of reducing the number of incomparability cases, we apply the same structure proposed in Larichev (2001), but modifying the comparison of pairs of alternatives according to the ideas proposed in Moshkovich et al. (2002). Figure 2 shows the structure of the comparison of alternatives process.

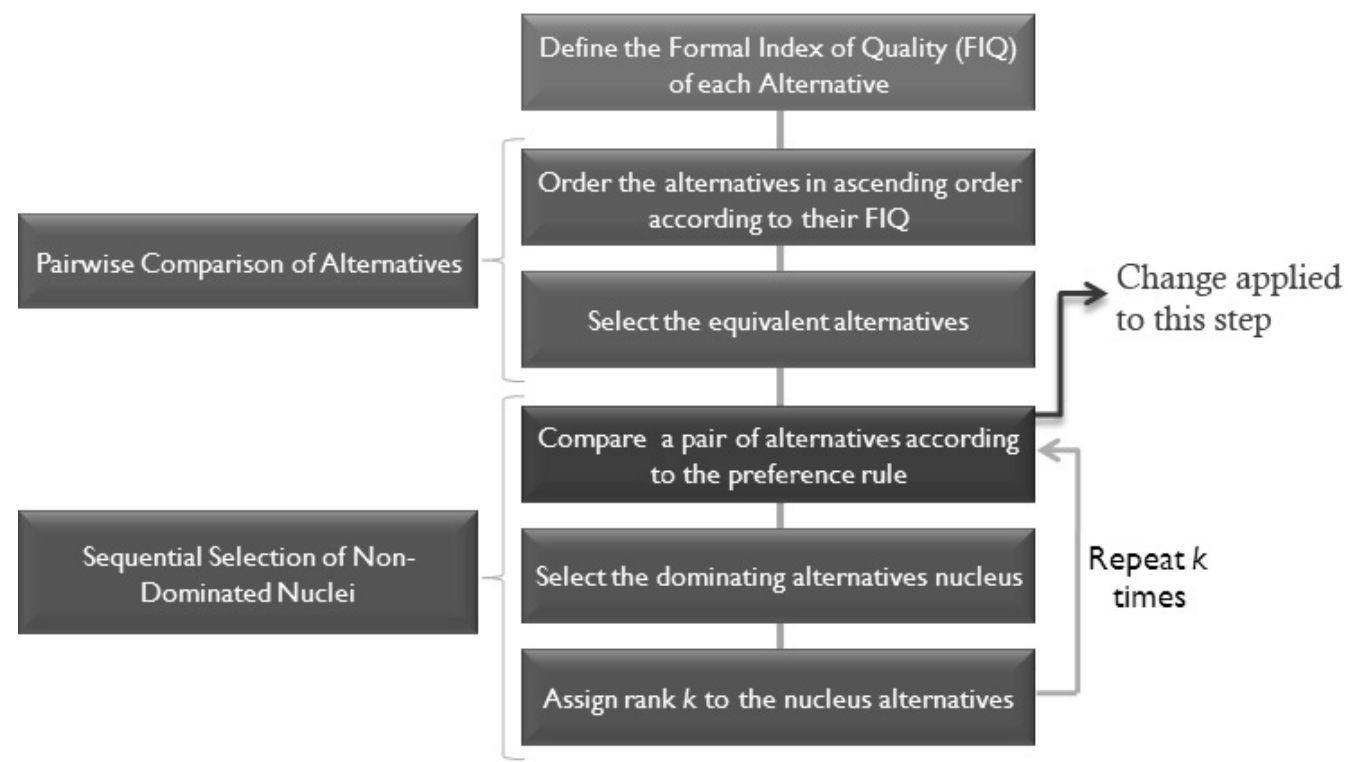

Figure 2 - Comparison of alternatives process. 
Each alternative has a function of quality - V(y) (Larichev, 2001a), depending on the evaluations of the criteria that it represents. In Moshkovich et al. (2002), it is proposed that the vectors of the ranking of the criteria values, which represent the function of quality, be rearranged in an ascending order. Then, the values will be compared to the corresponding position of the vector of values of another alternative based on the Pareto's dominance rule. Meanwhile, this procedure was modified for implementation because it was originally proposed to scales of preferences of criteria values, not for quality variation scales.

So, supposing the comparison between alternatives Alt1 $=\left\{A_{2}, B_{2}, C_{1}\right\}$ and Alt2 $=\left\{A_{3}, B_{1}\right.$, $\left.C_{2}\right\}$, and considering the scale of preferences: $a_{1} \prec b_{1} \prec c_{1} \prec a_{2} \prec b_{2} \prec c_{2} \prec a_{3} \prec b_{3} \prec$ $c_{3}$, we have the following functions of quality: $\mathrm{V}(\mathrm{Alt} 1)=(0,0,2)$ and $\mathrm{V}(\mathrm{Alt} 2)=(0,3,4)$, which represents the ranks of $b_{1}$ and $c_{1}, a_{2}$, respectively. Through the comparison of the ranks presented, we can say that Alt1 is preferable to Alt2.

However, there are cases in which the incomparability of real alternatives will not allow the presentation of a complete result, thus requiring further analysis. In such cases, we can evaluate all possible alternatives to the problem in order to rank the real alternatives indirectly. This process can be detailed as follows.

At the end of the comparison process, a graph representing the dominance relations between the alternatives can be structured. This way, through the inclusion of all possible alternatives to the problem in the comparison process (so that the absolute rank of each alternative would be obtained), one may be able to compare, by transitivity relations, alternatives that were classified as incomparable when the comparison of the real alternatives was performed. As an example, let us consider two real alternatives, $\mathrm{X}$ and $\mathrm{Y}$. When comparing these two alternatives, one realizes that they cannot be compared based on the dominance rules. However, when the comparison of all possible alternatives to the problem was performed, one finds that an imaginary alternative $\mathrm{Z}$ is dominated by $\mathrm{X}$ and dominates $\mathrm{Y}$. Then, by transitivity, we determine that $\mathrm{X}$ dominates $\mathrm{Y}$. Note that this is an elevated cost solution and should be performed only when it is necessary for the problem resolution.

\section{PROPOSED TOOL TO THE ZAPROS III- $i$ METHOD}

In order to facilitate the decision process and perform it consistently by observing its complexity so as to make it accessible, we present a tool implemented in Java, structured on the Verbal Decision Analysis, considering the proposed modifications to the methodology.

The tool is presented by the following sequence of actions:

- Criteria Definition: First of all, the user should define the criteria presented by the problem.

- Elicitation of preferences: Occurring in two stages: the elicitation of preferences for quality variation on the same criteria and the elicitation of preferences between pairs of criteria. 
- Alternatives Definition: The alternatives can be defined only after the construction of the scale of preferences.

- Alternatives Classification: After the problem formulation, the user can verify the solution obtained to the problem. The result is presented to the decision maker so that it can be evaluated. The comparison based on all possible alternatives to the problem is possible, but it should be performed only when it is necessary for the problem resolution, since it is an elevated cost solution.

\section{VALIDATION OF THE TOOL}

The computational models submitted to the tool will be presented so that it is possible to verify the improvements made to the ZAPROS III method. These models have previously known results, so it has been possible to compare their original result with that obtained through the tool. The problems, their original results and the results obtained from the application of the tool will be exposed next.

\subsection{Organizing a Fund for Investing Money in R\&D Projects}

The problem presented in "Ranking Multicriteria Alternatives: The Method ZAPROS III" (Larichev, 2001) was submitted to the tool. The work presents a model for aiding on the choice of an R\&D project for investing money.

The problem was formulated considering the criteria and values of criteria exposed in Table 1.

Table 1 - Criteria involved on the evaluation of R\&D projects.

\begin{tabular}{|c|c|}
\hline Criteria & Values of Criteria \\
\hline A - Originality & $\begin{array}{l}\text { A1. Absolutely new idea and/or approach; } \\
\text { A2. There are new elements in the proposal; } \\
\text { A3. Further development of previous ideas. }\end{array}$ \\
\hline B - Prospects & $\begin{array}{l}\text { B1. High probability of success; } \\
\text { B2. Success is rather probable; } \\
\text { B3. Success is hardly probable. }\end{array}$ \\
\hline $\mathrm{C}-$ Qualification & $\begin{array}{l}\text { C1. Qualification of the applicant is high; } \\
\text { C2. Qualification of the applicant is normal; } \\
\text { C3. Qualification of the applicant is unknown. }\end{array}$ \\
\hline
\end{tabular}

Figure 3 presents a step of the elicitation of preference process of the tool considering the quality variations of criteria $A$-Originality and $B$-Prospects.

The alternatives and their representations as criteria values, the ranks obtained from the application of the ZAPROS III and the ZAPROS III- $i$ methods are exposed in Table 2.

There were some differences in the ranking of the alternatives after the modifications made to the method: some alternatives that were set as incomparable when purely applying the ZAPROS III 
Aranaú Project

Start Problem Options Help

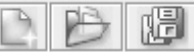

Elicitation of Preferences

\section{Elicitation of Preferences}

Based on the situations 1 and 2:

Situation 1:

'C - Qualification': C1. Qualification of the applicant is high

Situation 2:

'C - Qualification': C3. Qualification of the applicant is unknown

Compare criteria "A - Originality" and "B - Prospects", and select the preferable alternative on both situations:

'A2. There are new elements in the proposal'

'B1. High probability of success'

'A1. Absolutely new idea andior approach'

'B2. Success is rather probable'

The options above are equivalent

Save

Cancel

Figure 3 - Elicitation of preferences of criteria $A$-Originality and $B$-Prospects.

Table 2 - Possible R\&D projects for investing money and their ranks.

\begin{tabular}{|c|c|c|c|c|}
\hline \multirow{2}{*}{ Alternatives } & \multirow{2}{*}{ Criteria Values } & ZAPROS III & \multicolumn{2}{|c|}{ ZAPROS III- $i$ Rankings } \\
\cline { 3 - 5 } & & Ranking & Partial Ranking & Complete Ranking \\
\hline Alternative 1 & A1 B2 C1 & 2 & 2 & 2 \\
Alternative 2 & A2 B2 C1 & 3 & 3 & 3 \\
Alternative 3 & A3 B1 C2 & $3-4$ & 4 & 5 \\
Alternative 4 & A1 B3 C1 & 4 & 4 & 4 \\
Alternative 5 & A2 B1 C3 & $5-7$ & 5 & 7 \\
Alternative 6 & A3 B2 C2 & 6 & 6 & 8 \\
Alternative 7 & A3 B2 C1 & 5 & 5 & 6 \\
Alternative 8 & A3 B3 C1 & 7 & 7 & 9 \\
Alternative 9 & A2 B1 C2 & 1 & 1 & 1 \\
\hline
\end{tabular}


method are now comparable (for example, alternatives 2 and 3). Besides, the complete ranking of the alternatives was obtained by the comparison of all possible alternatives to the problem.

Figure 4 shows, respectively, the original graph of the alternatives, presented in Larichev (2001), the partial graph obtained from the application of the ZAPROS III- $i$ method to the problem, and the graph which was generated based on the comparison of all possible alternatives to the problem through the application of this method.
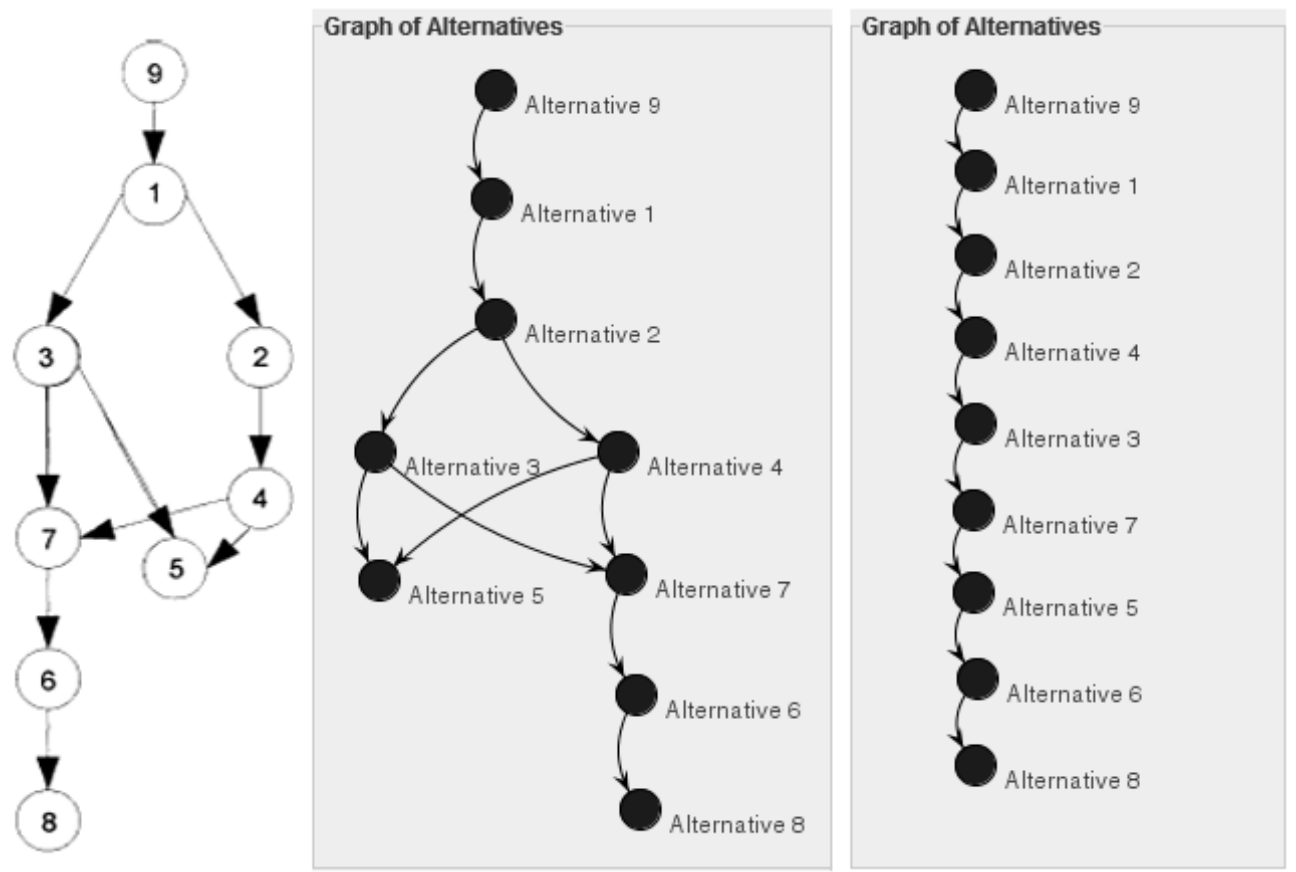

Figure 4 - Respectively, the original graph of the problem (Larichev, 2001), and the graphs obtained from the application of the problem to the ZAPROS III- $i$ method: the partial and the complete graphs.

Through the analysis of the graphs, we can state that the ZAPROS III- $i$ method achieved better results to the problem than the ones obtained through the application of the ZAPROS III one.

\subsection{Renting an Apartment or Room during a Period of Studies}

The problem of choosing an apartment or room during a period of studies is presented in Dimitriadi \& Larichev (2005). The work presents a model to analyze what would be the best place for a student to rent an apartment or room to live in, so that they can quickly get to the place of study, having an accessible rent price, considering the neighborhood where it is located and the furniture offered.

To do so, the problem was formulated considering the criteria and values of criteria presented in Table 3. The ZAPROS III method result and the ones obtained through the application of the tool to the problem are shown in Table 4. 
Table 3 - Criteria involved on the choice of an apartment or room to rent during a period of studies.

\begin{tabular}{|l|l|}
\hline Criteria & Values of Criteria \\
\hline A - Cost & $\begin{array}{l}\text { A1. Below the average cost for the neighborhood; } \\
\text { A2. About the average cost for the neighborhood; } \\
\text { A3. Above the average cost for the neighborhood. }\end{array}$ \\
\hline $\begin{array}{l}\text { B - Distance from } \\
\text { the underground }\end{array}$ & $\begin{array}{l}\text { B1. One can get to the underground in } 10 \text { minutes; } \\
\text { B2. One can get to the underground within half an hour; } \\
\text { B3. One can get to the underground within an hour or more. }\end{array}$ \\
\hline $\begin{array}{l}\text { C - Location of the apartment } \\
\text { of study (or work) }\end{array}$ & $\begin{array}{l}\text { C1. Place of employment (or institute) is located 3 or 4 } \\
\text { underground stops away from the apartment; }\end{array}$ \\
& $\begin{array}{l}\text { C2. lace of employment (or institute) and the apartment } \\
\text { are served by the same underground line; }\end{array}$ \\
& C3. Transfers are required in the underground. \\
\hline D - Type of the neighborhood & $\begin{array}{l}\text { D1. Safe neighborhood, protected zone, good landscaping; } \\
\text { D2. Fairly safe neighborhood, typical urban landscaping; }\end{array}$ \\
& D3. Dangerous neighborhood, industrial zone. \\
\hline E- Furniture & E1. Fully furnished apartment; \\
& E2. Partially furnished apartment; \\
& E3. Unfurnished apartment. \\
\hline
\end{tabular}

Table 4 - Possible places to rent during a period of studies and their ranks.

\begin{tabular}{|c|c|c|c|c|}
\hline \multirow{2}{*}{ Alternatives } & \multirow{2}{*}{ Criteria Values } & ZAPROS III & \multicolumn{2}{|c|}{ ZAPROS III $i$ Rankings } \\
\cline { 4 - 5 } & & Ranking & Partial Ranking & Complete Ranking \\
\hline Alternative 1 & A1 B2 C1 D2 E2 & 1 & 1 & 1 \\
Alternative 2 & A1 B2 C1 D2 E3 & 2 & 2 & 2 \\
Alternative 3 & A1 B2 C2 D3 E3 & 6 & 7 & 9 \\
Alternative 4 & A3 B1 C2 D3 E1 & 3 & 4 & 6 \\
Alternative 5 & A1 B1 C3 D2 E2 & 4 & 5 & 5 \\
Alternative 6 & A3 B3 C1 D2 E1 & 3 & 3 & 4 \\
Alternative 7 & A1 B1 C2 D1 E3 & 2 & 2 & 2 \\
Alternative 8 & A2 B2 C2 D2 E2 & 5 & 6 & 7 \\
Alternative 9 & A3 B3 C3 D1 E3 & 6 & 7 & 10 \\
Alternative 10 & A3 B2 C1 D1 E2 & 2 & 2 & 3 \\
\hline
\end{tabular}

The results obtained to the problem were almost the same, except for the comparison of alternatives 6 and 4, which were set as incomparable when applying the ZAPROS III method, and could be compared when the ZAPROS III- $i$ was applied. This led to the increase of the accuracy of one degree in the ranking for alternatives $3,4,5,8$ and 9.

Also, from the analysis of the partial ranking presented, one can notice that some alternatives had the same ranks (for example, alternatives 2, 7 and 10 had the same rank 2), which shows that these alternatives are incomparable. However, if the user asks for the comparison of all possible 
alternatives to the problem, a more detailed ranking of the alternatives is obtained. Then the final result of the problem then will be:

Alternative $1 \prec$ Alternative $10 \prec$ Alternative $7 \prec$ Alternative $2 \prec$ Alternative 6

$\prec$ Alternative $5 \prec$ Alternative $4 \prec$ Alternative $8 \prec$ Alternative $3 \prec$ Alternative 9 .

Thus, Figure 5 shows the original graph of the alternatives, presented in Dimitriadi \& Larichev (2005), and the graphs obtained through the application of the ZAPROS III- $i$ method to the problem: one considering the partial ranking of the alternatives, and the other, the graph generated from the comparison of all possible alternatives.
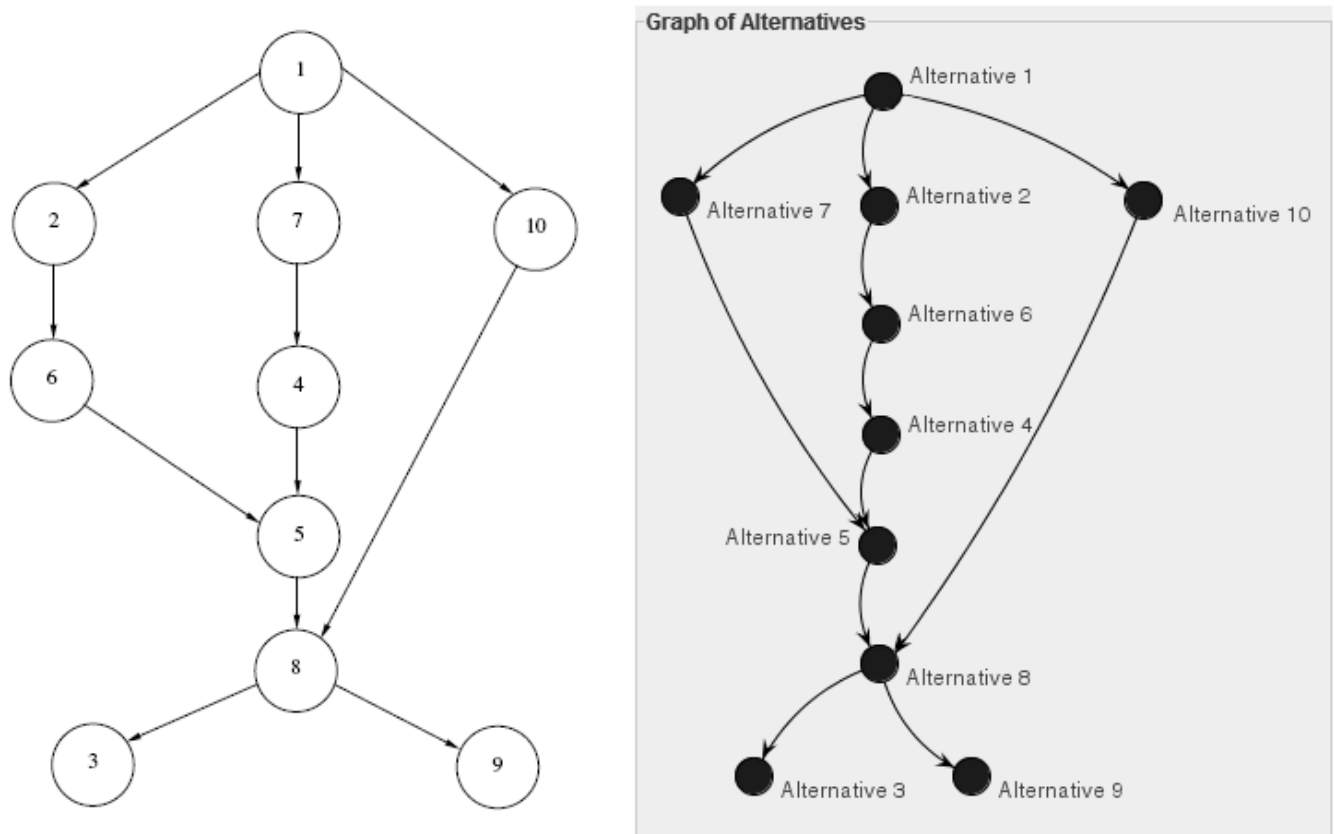

Figure 5 - Respectively, the original graph of the problem (source: Dimitriadi \& Larichev, 2005), and the graphs obtained through the application of the ZAPROS III $-i$ method, considering the partial and the complete comparison of the problem's alternatives.

Through the analysis of the graphs, we can verify an improvement in the comparison capacity of the method, which was obtained by the modification of the ZAPROS III method. This advance enabled the complete comparison of almost all the real alternatives to the problem. This way, a satisfactory result could be presented to the decision maker.

\subsection{The Choice of a Prototype for Digital Mobile Television}

The problem of choosing a prototype for digital mobile television (Tamanini et al., 2008) was also submitted to the tool. Five hypotheses were defined in the problem's modeling, according to Carvalho (2008), with the aim of helping the designers and analysts involved in the project 
define a questionnaire to gather the user's preferences about the different types of prototypes used. These hypotheses were also used in the formulation of the multi-criteria model, originating the criteria of the problem, and are defined as follows (Carvalho, 2008):

- Hypothesis 1: The evidence of the functions in the interface makes the use easier and influences the intensity of the user's attention required in the identification of the system functionalities;

- Hypothesis 2: The experience with similar applications will influence the user's choice of the preferred alternative;

- Hypothesis 3: The user's locomotion while manipulating the device will lead to the choice of the prototype that is easier to be used while one is moving;

- Hypothesis 4: The content has a decisive influence on the user's preferences, such that if the content used on the interface during the manipulation of the prototype is interesting for the user, it will exert a positive influence on the choice of this alternative;

- Hypothesis 5: The emotion felt by the user while using a determined interface exerts considerable influence on one's choice.

One criterion was defined to each hypothesis, being criterion A related to hypothesis 1, criterion B to hypothesis 2, and so on. The relevant criteria and their possible values are listed in Table 5.

Table 5 - Criteria involved on the choice of a prototype for mobile digital television.

\begin{tabular}{|l|l|}
\hline Criteria & Values of Criteria \\
\hline A - Functions Evidence & $\begin{array}{l}\text { A1. No difficulty was found on identifying the system functionalities; } \\
\text { A2. Some difficulty was found on identifying the system functionalities; } \\
\text { A3. It was hard to identify the system functionalities. }\end{array}$ \\
\hline $\begin{array}{l}\text { B - User's familiarity } \\
\text { with a determined } \\
\text { technology }\end{array}$ & $\begin{array}{l}\text { B1. No familiarity with similar applications is required; } \\
\text { B2. Little familiarity of the user with applications is required; } \\
\text { B3. The manipulation of the prototype is fairly easy when } \\
\text { the user is familiar with similar applications. }\end{array}$ \\
\hline $\begin{array}{l}\text { C - User's locomotion } \\
\text { while manipulating }\end{array}$ & $\begin{array}{l}\text { C1. The user was not confused when manipulating the } \\
\text { prototype while moving; } \\
\text { C2. The user was occasionally confused when manipulating the } \\
\text { prototype while moving; } \\
\text { C3. The user's spatial orientation in the application was } \\
\text { affected while moving. }\end{array}$ \\
\hline D - Content Influence & $\begin{array}{l}\text { D1. There is no influence of content on the choice of the interface; } \\
\text { D2. The content exerted some influence on the choice of the interface; } \\
\text { D3. The content was decisive on the choice of the interface. }\end{array}$ \\
\hline E- User's Emotion & $\begin{array}{l}\text { E1. The user felt fine (modern, comfortable, etc.) when using the interface; } \\
\text { E2. The user felt indifferent when using the interface; } \\
\text { E3. The user felt bad (uncomfortable, frustrated) when using the interface. }\end{array}$ \\
\hline
\end{tabular}


Three mobile interface prototypes were evaluated considering the user's point of view after using each one, and the information obtained was transformed into a scale of preferences. The three prototypes are defined in the next paragraphs.

The first prototype, defined as Alternative 1, represents the interaction project modeled in Mendes et al. (2008) (Carvalho, 2008), which was a version of the Digital Television (DTV) portal for mobile devices. Figure 6 shows the prototype's interface, which presents navigation arrows to move through the screens, and an indication of the current screen.
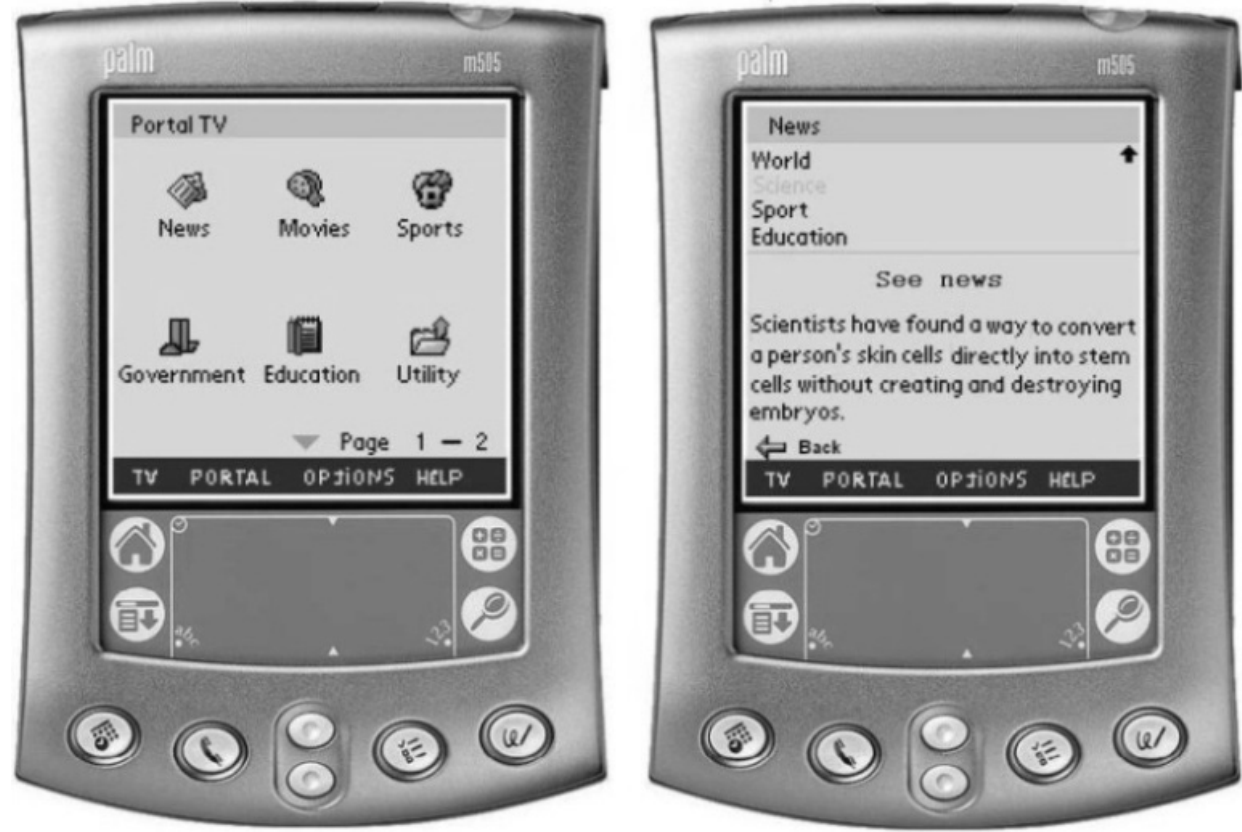

Figure 6 - Prototype similar to DTV applications, presenting navigation arrows.

Alternative 2 was developed considering similar applications of mobile devices, specially their operational systems, such as Palm OS. The Palm OS operational system presents elements similar of desktop applications adapted to touchscreen access and to the one-handed use of the device. The interface, shown in Figure 7, presents a scroll bar as the principal way of navigation.

The third interface proposal was based on desktop applications, using tabs to present the system functionalities. Alternative 3 contains a button to close the current screen and to get back to the previous one, which is similar to the one found in computer systems. The alternative is presented in Figure 8.

Through the use of the tool, both methods, the ZAPROS III and the ZAPROS III- $i$, were applied to the problem modeled and the results obtained are exposed in Table 6.

There was a difference in the final ranking considering the application of the ZAPROS III method and the ZAPROS III- $i$ one. Alternatives 2 and 3, which were incomparable according to the 

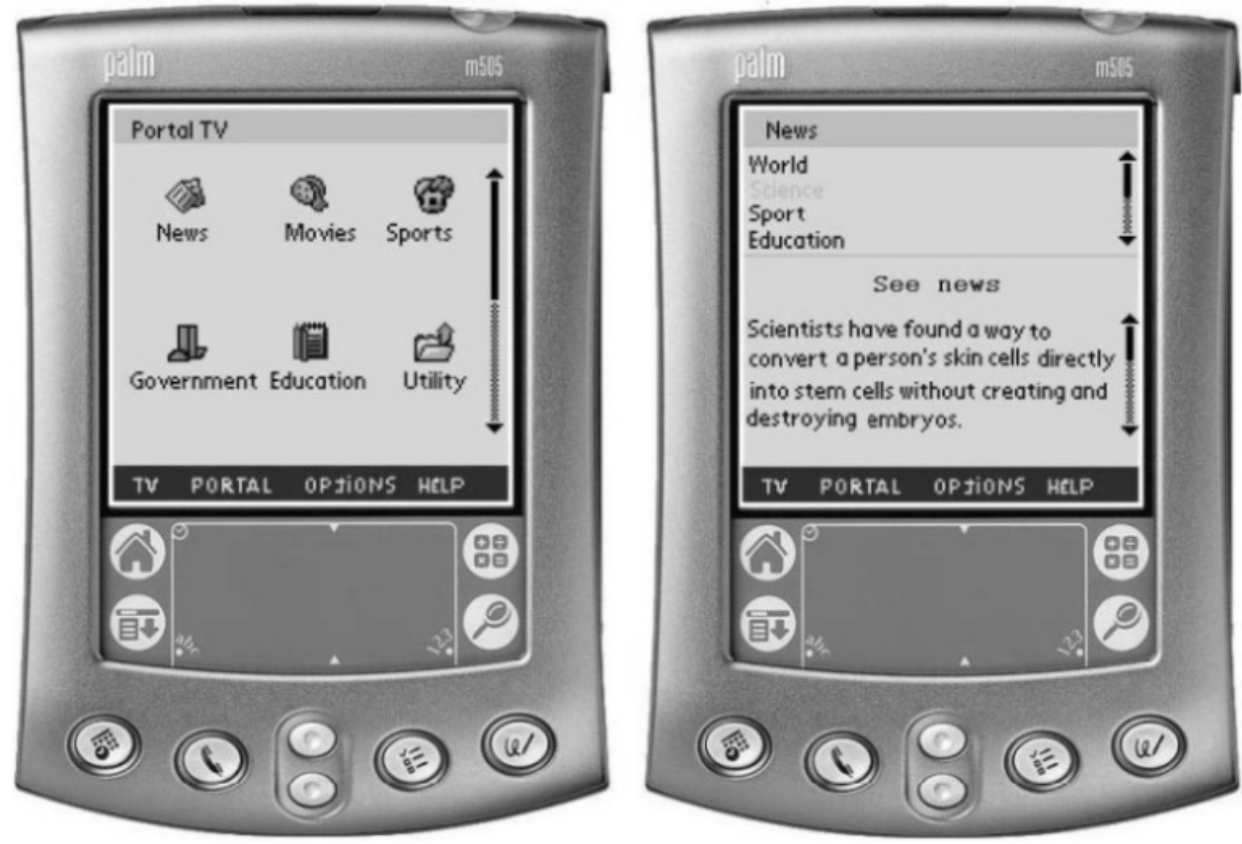

Figure 7 - Prototype similar to Palm applications, presenting navigation scroll bars.
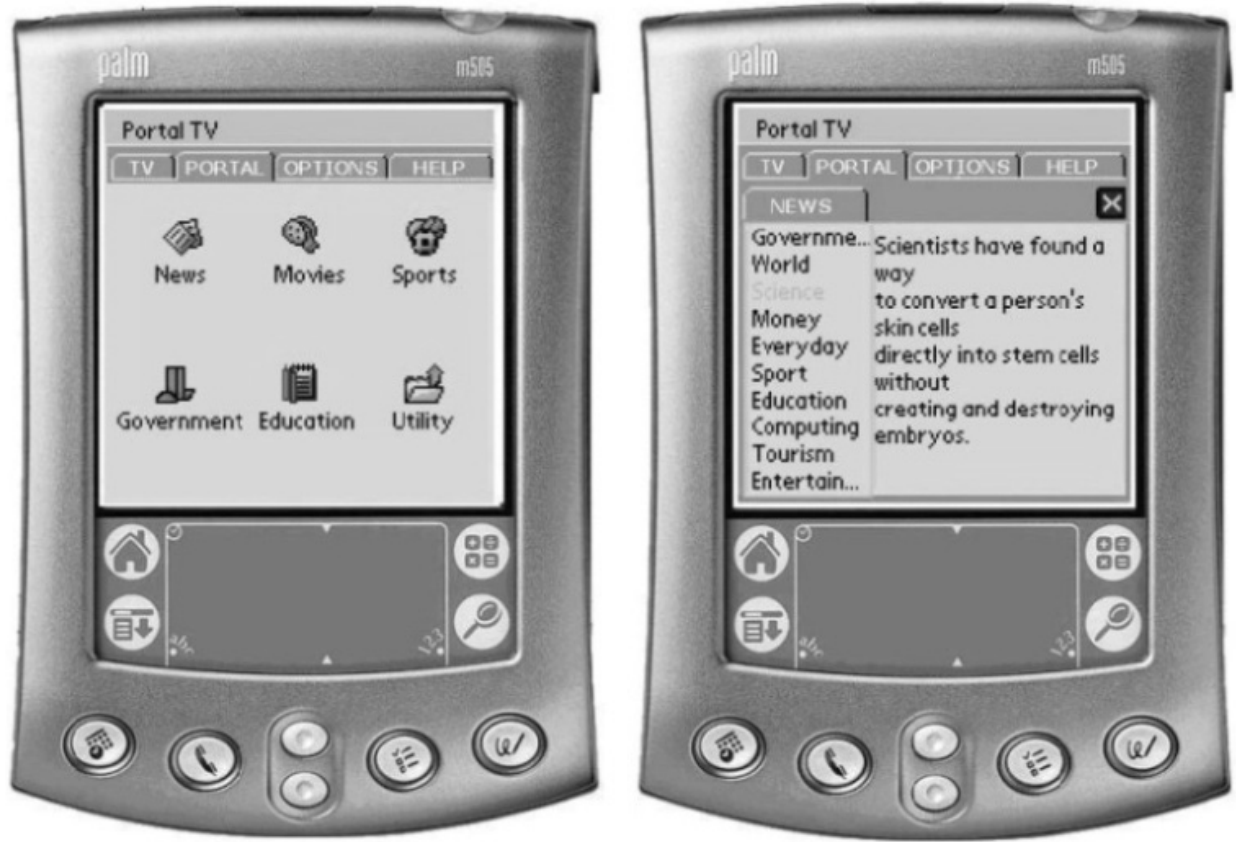

Figure 8 - Prototype similar to desktop applications, presenting navigation tabs. 
Table 6 - Possible prototypes for digital mobile television and their ranks.

\begin{tabular}{|c|c|c|c|c|}
\hline \multirow{2}{*}{ Alternatives } & \multirow{2}{*}{ Criteria Values } & ZAPROS III & \multicolumn{2}{|c|}{ ZAPROS III- $i$ Rankings } \\
\cline { 4 - 5 } & & Ranking & Partial Ranking & Complete Ranking \\
\hline Prototype 1 & A2 B1 C2 D1 E2 & 2 & 2 & 3 \\
Prototype 2 & A2 B3 C1 D1 E1 & 2 & 2 & 2 \\
Prototype 3 & A2 B1 C1 D1 E2 & 1 & 1 & 1 \\
\hline
\end{tabular}

ZAPROS III method, are now comparable considering the evaluation of all possible alternatives to the problem. This way, it was possible to obtain the complete ordering of the set of alternatives. The comparison of the graphs obtained on both applications is presented in Figure 9.

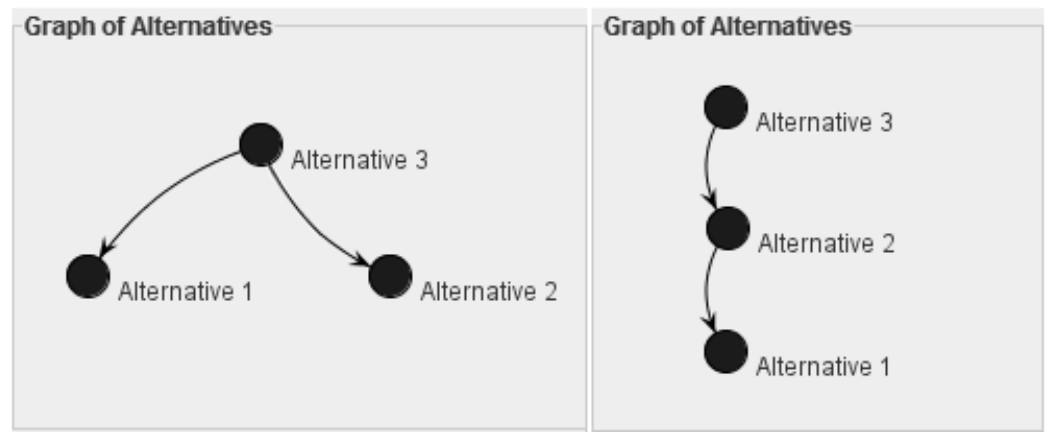

Figure 9 - The graphs obtained through the application of the ZAPROS III- $i$ method to the problem, where the first one was obtained from the comparison of the real alternatives to the problem, which was the same as the one obtained through the ZAPROS III one (Larichev, 2001), and the other was generated based on the comparison of all possible alternatives to the problem.

\section{CONCLUSIONS}

This work discusses the qualitative decision-making methods, which belong to the Verbal Decision Analysis framework, particularly the ZAPROS III method. The main advantage of this method is that the presentation of all questionings during the elicitation of preferences process is done in the decision maker's natural language, and the comparison between the values of criteria is verbal, respecting the limitations of the human information processing system. The incomparability cases, however, are unavoidable when the scale of preferences is purely verbal, since there is no exact measure of the values.

One of the contributions of this work is the application of some modifications to the ZAPROS III method in order to improve the comparison of alternatives process concerning the incomparability cases. The modified methodology is applied by the Aranaú tool, a computational implementation which allows aiding the decision-making process and performing it in a reliable and faster way. 
In such a case, the modified methodology applies:

- The Formal Index of Quality (FIQ) (Larichev, 2001), which was used with the purpose of reducing the number of pairs of alternatives to be compared;

- The ideas of comparison between alternatives by ordering the values of quality vectors in an ascending order (Moshkovich et al., 2002); and

- The comparison considering all the possible alternatives to the problem for complex decision-making processes.

To validate the modifications applied to the methodology and, consequently, the proposed tool, some previously structured problems applying the ZAPROS III method were used, so that it was possible to make a comparison between the results.

Through the analysis of the results obtained for the exposed problems, it was possible to verify that the modified methodology was more efficient than the ZAPROS III method considering the exposed problems. Besides, through the comparison of all possible alternatives to the problem, the complete ranking of the alternatives was obtained in three of the five tested experiments, and, for the ones where it was not possible to generate the complete ranking, only a few alternatives remained incomparable.

As a conclusion of the structuring of the tool, the expected behavior was verified in all tested situations through the presentation of satisfactory results at the end of its execution.

As future works, we intend to improve the treatment proposed to the incomparability cases, reducing the complexity they represent and, consequently, the execution cost of the procedure. Also, new experiments applying the proposed methodology to a multicriteria model aiming at the early diagnosis of the Alzheimer's disease are in progress (Tamanini et al., 2010b) and (Tamanini, 2010e).

\section{ACKNOWLEDGEMENTS}

The authors are thankful to the National Council for Scientific and Technological Development (CNPq) and to Celestica do Brasil for all the support received on this project.

\section{REFERENCES}

[1] ASHIKHMIn I \& FUREMS E. 2006. UniComBOS - Intelligent decision support system for multicriteria comparison and choice. Journal of Multi-criteria Decision Analysis, 13(2): 147-157.

[2] Carvalho ALA De. 2008. Análise de Alternativas de Projeto de Interação Aplicando Análise Verbal de Decisão. Dissertação de Mestrado, Mestrado em Informática Aplicada, Universidade de Fortaleza.

[3] Castro AKA, Pinheiro PR \& Pinheiro MCD. 2009. An Approach for the Neuropsychological Diagnosis of Alzheimer's Disease: A Hybrid Model in Decision Making. Rough Sets and Knowledge 
Technology (RSKT). Lecture Notes in Computer Science, 5589: 216-223. DOI: 10.1007/978-3-64202962-2.

[4] Dimitriadi GG \& Larichev O. 2005. Decision Support System and the ZAPROS III Method for Ranking the Multiattribute Alternatives with Verbal Quality Estimates. Automation and Remote Control, 66(8): 1322-1335.

[5] Evangelou C, Karacapilidis N \& Khaled OA. 2005. Interweaving knowledge management, argumentation and decision making in a collaborative setting: the KAD ontology model. Int. J. of Knowledge and Learning, 1(1/2): 130-145.

[6] Gomes lfam, Moshkovich H \& Torres A. 2010. Marketing decisions in small businesses: how verbal decision analysis can help. International Journal Management and Decision Making, 11(1): 19-36. DOI: 10.1504/IJMDM.2010.033641.

[7] Larichev O \& Moshkovich HM. 1997. Verbal decision analysis for unstructured problems. Kluwer Academic Publishers, Boston.

[8] LARICHEV O. 2001. Ranking Multicriteria Alternatives: The Method ZAPROS III. European Journal of Operational Research, 131: 550-558.

[9] LARICHeV O. 2001a. Method ZAPROS for Multicriteria Alternatives Ranking and the Problem of Incomparability. Informatica, 12(1): 89-100.

[10] Manoselis N \& Costopoulou C. 2008. Preliminary Study of the Expected Performance of MAUT Collaborative Filtering Algorithms. Communications in Computer and Information Science, 19(1): 527-536. DOI: 10.1007/978-3-540-87783-7_67.

[11] Mendes M, Carvalho Al, Furtado Mes \& Pinheiro PR. 2008. Co-evolutionary Interaction Design of Digital TV Applications Based on Verbal Decision Analysis of User Experiences. Communications in Computer and Information Science, 19(1): 702-711. DOI: 10.1007/978-3-54087783-7_89.

[12] Moshkovich H, Mechitov A \& Olson D. 2005. Verbal decision analysis. In: Figueira J, GRECO S \& EHRGOTT M. (Eds.): Multiple criteria decision analysis: state of the art surveys, Series: International Series in Operations Research \& Management Science, Springer, 78: 609-637.

[13] Moshkovich H, Mechitov A \& Olson D. 2002. Ordinal Judgments in Multiattribute Decision Analysis. European Journal of Operational Research, 137(3): 625-641.

[14] Nunes LC, Pinheiro PR, Pequeno TC \& Pinheiro MCD. 2011. Toward an Applied to the Diagnosis of Psychological Disorders. Special Issue: Software Tools and Algorithms for Biological Systems, Springer, Advances in Experimental Medicine and Biology, 696(7): 573-580. DOI: 10.1007/978-1-4419-7046-6_58.

[15] Pinheiro PR, Sousa GGC \& CAstro AKA DE. 2008. Estruturação do Problema Multicritério para Produção de Jornal. Pesquisa Operacional, 28(2): 203-216. DOI: 10.1590/S010174382008000200002.

[16] Tamanini i, Machado TCS, Mendes MS, Carvalho Al, Furtado MES \& Pinheiro PR. 2008. A Model for Mobile Television Applications Based on Verbal Decision Analysis. In: TAREK SoBH. (Org.). Advances in Computer Innovations in Informations Sciences and Engineering, Springer, 1: 399-404. DOI: 10.1007/978-1-4020-8741-7_72. 
[17] TAmanini I \& Pinheiro PR. 2008. Applying a New Approach Methodology with ZAPROS. In: XL Brazilian Symposium of Operational Research, 2008, João Pessoa. Proceedings of XL Brazilian Symposium of Operational Research, 914-925.

[18] Tamanini I, Pinheiro PR, Carvalho AL \& Castro AKA. 2009a. A Novel Multicriteria Model Applied to Cashew Chestnut Industrialization Process. In: Jorn Mehnen, Ashutosh Tiwari, Mario Koppen \& Ashraf SaAd. (Org.). Applications of Soft Computing, Springer, 58: 243-252. DOI: $10.1007 / 978-3-540-89619-724$.

[19] Tamanini I, Castro AKA, Pinheiro PR \& Pinheiro MCD. 2009b. Towards an Applied Multicriteria Model to the Diagnosis of Alzheimer's Disease: A Neuroimaging Study Case. In: 2009 IEEE International Conference on Intelligent Computing and Intelligent Systems, 2009, Shanghai, China. Proceedings of the 2009 IEEE International Conference on Intelligent Computing and Intelligent Systems. Beijing: IEEE Press, 3, 652-656. DOI: 10.1109/ICICISYS.2009.5358087.

[20] Tamanini I, Castro AKA, Pinheiro PR \& Pinheiro MCD. 2009c. Towards the Early Diagnosis of Alzheimer's Disease: A Multicriteria Model Structured on Neuroimaging. International Journal of Social and Humanistic Computing, 1(2): 203-217. DOI: 10.1504/IJSHC.2009.031008.

[21] Tamanini I, Castro AKA, Pinheiro PR \& Pinheiro MCD. 2011. Verbal Decision Analysis Applied on the Optimization of Alzheimer's Disease Diagnosis: A Study Case Based on Neuroimaging. Special Issue: Software Tools and Algorithms for Biological Systems, Advances in Experimental Medicine and Biology. Springer, 696(7): 555-564. DOI: 10.1007/978-1-4419-7046-6_56.

[22] Tamanini I, Pinheiro PR \& Pinheiro MCD. 2010a. Analysis of Verbal Decision Analysis Methods Considering a Multicriteria Model to the Diagnosis of Alzheimer's Disease. Proceedings of the International Conference on Bioinformatics and Computational Biology (BIOCOMP), 2: 526531.

[23] Tamanini I, Pinheiro PR \& Pinheiro MCD. 2010b. The Neuropathological Diagnosis of the Alzheimer's Disease under the Consideration of Verbal Decision Analysis Methods. In: Fifth International Conference on Rough Set and Knowledge Technology (RSKT), Lecture Notes in Computer Science, 6401, 427-432. DOI: 10.1007/978-3-642-16248-0.

[24] Tamanini I, Pinheiro PR \& Pinheiro MCD. 2010c. The Choice of Neuropathological Questionnaires to Diagnose the Alzheimer's Disease Based on Verbal Decision Analysis Methods. International Conference on Information Computing and Applications (ICICA), Lecture Notes in Computer Science, 6377, 549-566. DOI: 10.1007/978-3-642-16167-4_70.

[25] TAMANINI I. 2010e. Improving the ZAPROS Method Considering the Incomparability Cases, Master's thesis, Graduate Program in Applied Informatics, University of Fortaleza.

[26] Pinheiro PR, Tamanini I, Silva Filho FC da \& Reis Filho MAM. 2010d. Applying Verbal Decision Analysis on the Choice of Materials to the Construction Process of Earth Dams. International Conference on Information Computing and Applications (ICICA), Lecture Notes in Computer Science, 6377, 557-564. DOI: 10.1007/978-3-642-16167-4_71.

[27] Ustinovich L \& Kochin D. 2004. Verbal Decision Analysis Methods for Determining the Efficiency of Investments in Construction. Foundations of Civil and Environmental Engineering, 5: 35-46. 